\title{
Terahertz Photoconductivity of Graphene Nanostructures
}

Jensen, Søren A.; Ulbricht, Ronald; Narita, Akimitsu; Feng, Xinliang; Müllen, Klaus; Turchinovich, Dmitry; Hertel, Tobias; Bonn, Mischa

\section{Published in:}

Proceedings of the 38th International Conference on Infrared, Millimeter and Terahertz Waves IRMMW-THz 2013

Link to article, DOI:

10.1109/IRMMW-THz.2013.6665852

Publication date:

2013

Link back to DTU Orbit

Citation (APA):

Jensen, S. A., Ulbricht, R., Narita, A., Feng, X., Müllen, K., Turchinovich, D., Hertel, T., \& Bonn, M. (2013).

Terahertz Photoconductivity of Graphene Nanostructures. In Proceedings of the 38th International Conference on Infrared, Millimeter and Terahertz Waves IRMMW-THz 2013 IEEE. https://doi.org/10.1109/IRMMW-

THz.2013.6665852

\section{General rights}

Copyright and moral rights for the publications made accessible in the public portal are retained by the authors and/or other copyright owners and it is a condition of accessing publications that users recognise and abide by the legal requirements associated with these rights.

- Users may download and print one copy of any publication from the public portal for the purpose of private study or research.

- You may not further distribute the material or use it for any profit-making activity or commercial gain

- You may freely distribute the URL identifying the publication in the public portal 


\title{
Terahertz Photoconductivity of Graphene Nanostructures
}

\author{
Søren A. Jensen ${ }^{\mathrm{a}, \mathrm{b}}$, Ronald Ulbricht ${ }^{\mathrm{b}}$, Akimitsu Narita ${ }^{\mathrm{a}}$, Xinliang Feng ${ }^{\mathrm{a}}$, Klaus Müllen ${ }^{\mathrm{a}}$, Dmitry \\ Turchinovich $^{\mathrm{a}, \mathrm{c}}$, Tobias Hertel ${ }^{\mathrm{d}}$, and Mischa Bonn ${ }^{\mathrm{a}}$ \\ ${ }^{a}$ Max Planck Institute for Polymer Research, Mainz, Germany. \\ ${ }^{\mathrm{b}}$ FOM Institute for Atomic and Molecular Physics, Amsterdam, The Netherlands. \\ ${ }^{c}$ DTU Fotonik, Technical University of Denmark, Lyngby, Denmark \\ ${ }^{\mathrm{d}}$ Institute of Physical and Theoretical Chemistry, Julius-Maximilian University, Wurzburg, Germany.
}

The photoconductive properties of graphene nanoribbons and carbon nanotubes were studied using optical pump-THz probe spectroscopy. A reduction in conductivity of GNRs compared to CNTs was observed.

\section{INTRODUCTION AND BACKGROUND}

$\mathrm{R}^{\mathrm{c}}$ ecently a "bottom-up" approach was developed for producing long graphene nanoribbons (GNRs) with welldefined edge structures and widths down to $\sim 1 \mathrm{~nm}$, possessing bandgaps corresponding to visible wavelengths [1]. The structure of these GNRs is shown in Figure 1. Carbon nanotubes (CNTs), are structurally very similar to GNRs, only 'rolled up' in the lateral dimension. Here, we studied semiconducting $(6,5)$ type CNTs as shown in Figure 2. We present a comparative study of the transient photoconductivity of structurally defined GNRs and semiconducting CNTs, employing optical pump - $\mathrm{THz}$ probe spectroscopy to investigate the photogenerated species on sub ps timescales. Here charge carriers are optically excited in the sample material by an ultrashort laser pulse, and probed by a freely propagating, single cycle electromagnetic pulse consisting of frequencies in the 0.3-1.6 THz range. A schematic of the experimental setup is shown in Figure 3. The setup is driven by an amplified pulsed laser system which delivers pulses of $800 \mathrm{~nm}$ central wavelength and sub - $100 \mathrm{fs}$ duration at a repetition rate of $1 \mathrm{kHz}$. A portion of these pulses (the pump beam in Figure 3) is used to photo-excite the sample directly; alternatively, the excitation wavelength can be altered first either by optical doubling crystals or by an optical parametric amplifier (OPA). Another portion of the laser beam (the generation beam) generates the $\mathrm{THz}$ probe in a $\mathrm{ZnTe}$ crystal by a process known as optical rectification [3]. The THz probe is focused on the sample, and then refocused on a second ZnTe crystal where it is combined with a third beam, the sampling beam. In this second $\mathrm{ZnTe}$ crystal the timedependent electric field of the $\mathrm{THz}$ probe pulse is directly measured using free-space electrooptic sampling (FEOS) - an inverse optical rectification effect [3]. The electric field in the $\mathrm{THz}$ pulse is proportional to the ellipticity of the sampling laser beam, which is analyzed optically via a variable wave plate, a Wollaston prism (or polarizing beam splitter), and a pair of photodiodes. The differential voltage on the photodiodes, proportional to the $\mathrm{THz}$ field strength, is recorded with lock-in detection as function of the delay between the $\mathrm{THz}$ pulse and the sampling laser pulse.

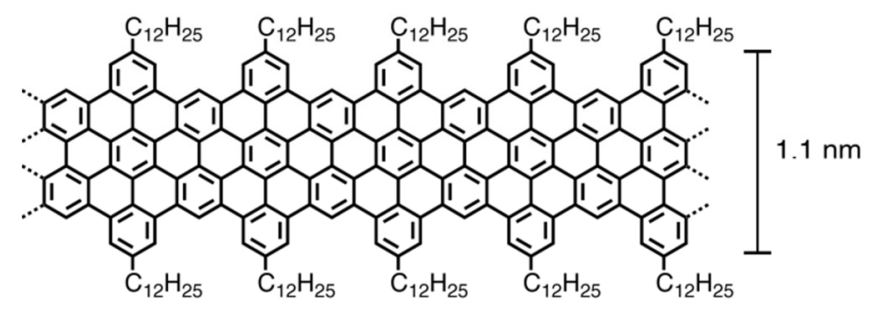

Figure 1 Molecular structure of graphene nanoribbon (GNR) of length $600 \mathrm{~nm}$ and effective bandgap $1.88 \mathrm{eV}$.

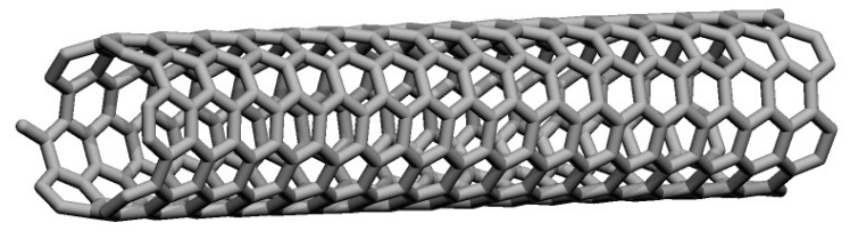

Figure 2 Molecular structure of semiconducting (6,5) carbon nanotube [2].

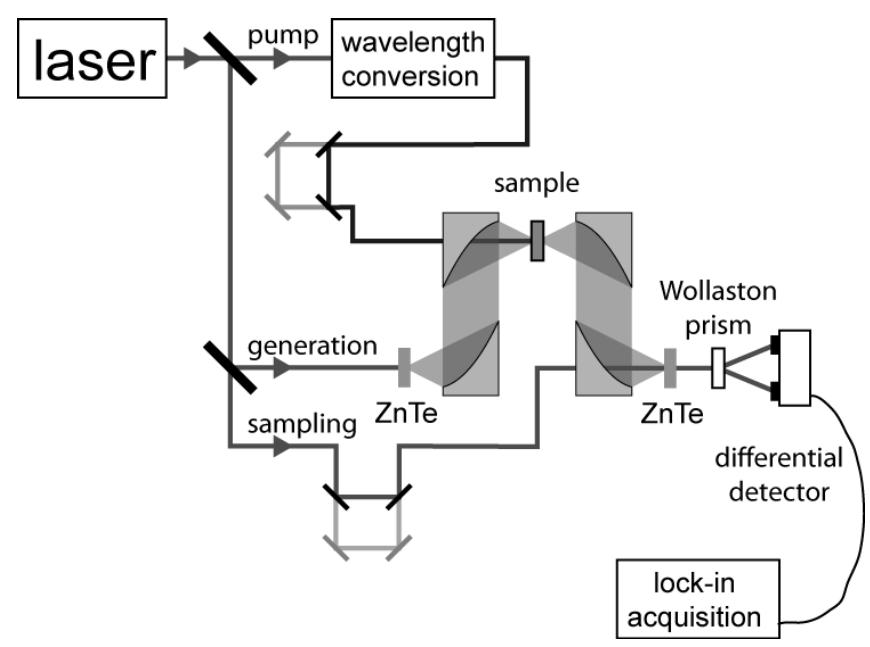

Figure 3 Sketch of optical pump - THz probe experimental setup.

\section{RESULTS}

Figure 4 shows the frequency-resolved real part of the photoconductivity of the GNRs, measured 300 fs after photoexcitation at $400 \mathrm{~nm}$ wavelength. A positive real conductivity is observed, increasing in magnitude with probe 
frequency. The real part of the photoconductivity of CNTs, measured $300 \mathrm{fs}$ after photoexcitation at $800 \mathrm{~nm}$ wavelength, is also shown in Figure 4. It peaks at around $1 \mathrm{THz}$. The conductivity of CNTs per absorbed photon is more than an order of magnitude higher than for GNRs. This is consistent with theoretical calculations [4] that have predicted significantly larger carrier mobilities for the CNTs than the GNRs for the materials with the bandgaps presented here.

The different possible causes for the different conductivities and the comparison to theory [4] are at the focus of our current work, and will be discussed in more detail in our contribution.

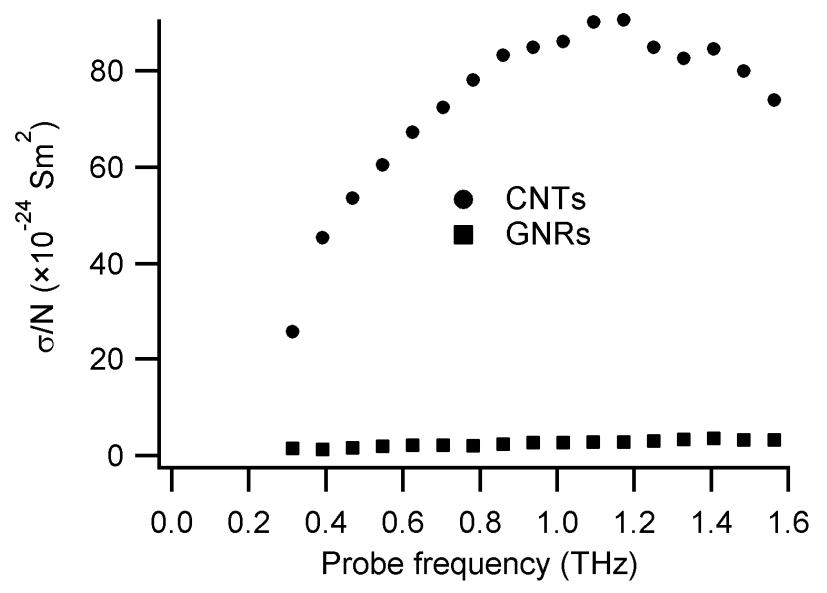

Figure 4 Real conductivity normalized by absorbed photon density for carbon nanotubes (CNTs) and graphene nanoribbons (GNRs).

\section{REFERENCES}

[1] Chen, L. et al., "From Nanographene and Graphene Nanoribbons to Graphene Sheets: Chemical Synthesis" Angew. Chem., Int. Ed. $2012, \mathbf{5 1}, 7640$.

[2] Structure calculated with: TubeGen 3.4 (web-interface, http://turin.nss.udel.edu/research/tubegenonline.html), J. T. Frey and D. J. Doren, University of Delaware, Newark DE, 2011. And plotted with: QuoteMol, Marco Tarini, et al. "Ambient Occlusion and Edge Cueing for Enhancing Real Time Molecular Visualization" IEEE Transactions on Visualization and Computer Graphics 12, 1237-1244, 2006.

[3] R. Ulbricht, et al., "Carrier dynamics in semiconductors studied with time-resolved terahertz spectroscopy", Rev Mod Phys, 83, 543, 2011.

[4] B. Obradovic, et al., "Analysis of graphene nanoribbons as a channel material for field-effect transistors", Appl Phys Lett 88, 14, 2006 . 